\title{
Structural and Electrochemical Properties of Al-Added Molybdate Conversion Coatings on Zinc
}

\author{
Dong-Jun Lee ${ }^{1}$, Tak Kang ${ }^{1}$, Hun-Joon Sohn ${ }^{1}$ * and Hyung-Joon Kim ${ }^{2}$ \\ ${ }^{1}$ School of Materials Science and Engineering, Seoul National University, Seoul, 151-742, Korea \\ ${ }^{2}$ Coating Technology \& Electrical Steel Research Steel Group, Pohang Iron \& Steel Co., Ltd. 790-785, Korea
}

\begin{abstract}
Molybdate conversion coatings were deposited on zinc substrate in the presence of Al to improve the corrosion resistance and their structural and electrochemical properties were characterized with various analytical techniques. Infrared reflectance spectroscopy analysis indicated that $\mathrm{Al}$ existed as $\mathrm{Al}(\mathrm{OH})_{3}$ in the molybdate conversion coatings. It was found that the addition of Al to molybdate conversion coatings hindered the oxygen reduction and hydrogen evolution reactions effectively compared with pure molybdate conversion coatings, resulting in the enhanced anticorrosive property.
\end{abstract}

(Received September 12, 2001; Accepted November 26, 2001)

Keywords: aluminum addition, molybdate conversion coatings, anticorrosive property, Raman spectroscopy, infrared reflectance spectroscopy

\section{Introduction}

Chromate conversion coatings have been used extensively not only to protect the galvanized steel surfaces from corrosion but also to provide improved paint adhesion and good surface finish. Recently, many investigations have been carried out to replace chromate conversion coatings by more environmentally friendly ones, namely, molybdates, tungstates, permanganates, and vanadates ${ }^{1-7)}$ because of the toxic nature of hexavalent chromium to the environment. Among these, molybdate conversion coatings obtained in the $\mathrm{pH}$ range of 5.0-5.5 shows relatively good performance of corrosion resistance, although its anticorrosive property is still poor compared with chromate conversion coatings. ${ }^{1-3,6,7)}$

Since the molybdate conversion coatings are noncrystalline in nature and there are a number of oxides with a composition of $\mathrm{MoO}_{x}(2 \leq x \leq 3)$, $\left.{ }^{8}\right)$ the structure of the conversion coatings was not known exactly except a few results of XPS analyses. ${ }^{1,6)}$ The poor anticorrosive performance of molybdate conversion coatings, compared with chromate conversion coatings encouraged some investigators to attempt to add other coating agents for synergetic effects. ${ }^{2,5,9,10)}$

Tang et al., suggested molybdate/phosphate conversion coatings which exhibited good corrosion resistance, especially during outdoor exposure trials. ${ }^{5}$ ) And Fang et al., also claimed that conversion coatings obtained with $\mathrm{Si}-\mathrm{Mo}$ heteropoly acid on steel have a good anticorrosive property. ${ }^{9}$ ) But there were no apparent synergistic effects in dual formation treatments which were performed by immersion into each molybdate and permanganate solution in ordinary and reverse sequences. $^{2)}$

In this study, the effect of $\mathrm{Al}$ addition to molybdate conversion coatings on corrosion resistance and the structure of molybdate conversion coatings were examined using electrochemical experiments and spectroscopic methods.

\section{Experimental}

Molybdate conversion coatings were prepared by dipping zinc electrode in various solutions, of which compositions are listed in Table 1. Prior to dipping, zinc electrode of $1 \mathrm{~cm}^{2}$ was polished with $\mathrm{SiC}$ sand paper (\#2000) followed by rinsing with distilled water and dried in air. Electrochemical experiments were performed in a borate buffer solution using potentiostat/galvanostat (EG\&G, PARC 273A), which was coupled with the rotator $(E G \& G, 616)$. A saturated calomel electrode (SCE) was used as a reference electrode and a graphite rod as a counter electrode, and the borate buffer solution was composed of $0.15 \mathrm{kmol} / \mathrm{m}^{3} \mathrm{Na}_{2} \mathrm{~B}_{4} \mathrm{O}_{7}$ and $0.3 \mathrm{kmol} / \mathrm{m}^{3} \mathrm{H}_{3} \mathrm{BO}_{3}$ with $\mathrm{pH}$ of 8.8. To control the concentration of the dissolved oxygen in the borate buffer solution, the solution was continuously bubbled with purified $\mathrm{N}_{2}$ or $\mathrm{O}_{2}$ gas during experiments, and the concentration of dissolved oxygen was measured by a dissolved oxygen meter (Istek, 215D). The saturated concentration of the dissolved oxygen is approximately $39 \mathrm{ppm}$ during oxygen bubbling and $0.2 \mathrm{ppm}$ during nitrogen bubbling.

Raman spectra were obtained using a Raman spectrophotometer (Jobin-Yvon, Model T64000). Infrared reflectance spectra were acquired using a FT-IR spectrometer (Bruker, IFS 113v). The composition-depth profiles of molybdate conversion coatings were obtained by Auger electron spectroscopy (Perkin-Elmer, Physical Electronic Inc., Model 660) and the sample surface was sputtered using argon ion beam with a sputtering rate of $9 \mathrm{~nm} / \mathrm{min}\left(\mathrm{SiO}_{2}\right)$. The amount of Mo in conversion coatings was analyzed by inductively coupled plasma atomic emission spectroscopy, ICP-AES (Shimadzu, ICPQ 1000). The surface morphology was observed using an atomic force microscope (PSI, Autoprobe cp) in contact mode with a microlever. HR-TEM (JEOL, JSM-6330F) images and FE-SEM images (JEOL, JEM-3000F) were obtained to identify the amorphous nature and the thickness of the conversion coatings, respectively. 
Table 1 Composition and $\mathrm{pH}$ of treatment solutions.

\begin{tabular}{|c|c|c|c|c|c|c|}
\hline Bath & MO1 & MO2 & MA1 & MA2 & MA3 & CH1 \\
\hline $\mathrm{pH}$ & 5.0 & 3.0 & 3.0 & 3.0 & 3.0 & 3.0 \\
\hline $\begin{array}{l}\text { Composition } \\
\text { (concentration, } \\
M / \mathrm{kmol} \mathrm{m}^{-3} \text { ) }\end{array}$ & $\begin{array}{c}\mathrm{Na}_{2} \mathrm{MoO}_{4} \\
(0.1)\end{array}$ & $\begin{array}{c}\mathrm{Na}_{2} \mathrm{MoO}_{4} \\
(0.1)\end{array}$ & $\begin{array}{c}\mathrm{Na}_{2} \mathrm{MoO}_{4} \\
\quad(0.1) \\
\mathrm{Al}_{2}\left(\mathrm{SO}_{4}\right)_{3} \\
(0.015)\end{array}$ & $\begin{array}{c}\mathrm{Na}_{2} \mathrm{MoO}_{4} \\
(0.1) \\
\mathrm{Al}_{2}\left(\mathrm{SO}_{4}\right)_{3} \\
(0.05)\end{array}$ & $\begin{array}{c}\mathrm{Na}_{2} \mathrm{MoO}_{4} \\
(0.1) \\
\mathrm{Al}_{2}\left(\mathrm{SO}_{4}\right)_{3} \\
(0.15)\end{array}$ & $\begin{array}{c}\mathrm{K}_{2} \mathrm{Cr}_{2} \mathrm{O}_{7} \\
(0.05)\end{array}$ \\
\hline
\end{tabular}

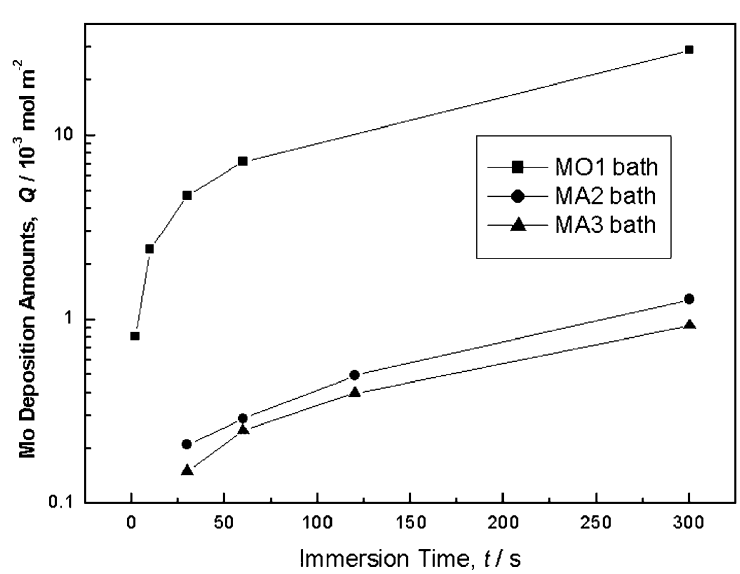

Fig. 1 Mo content in conversion coatings obtained from MO1, MA2, MA3 baths.

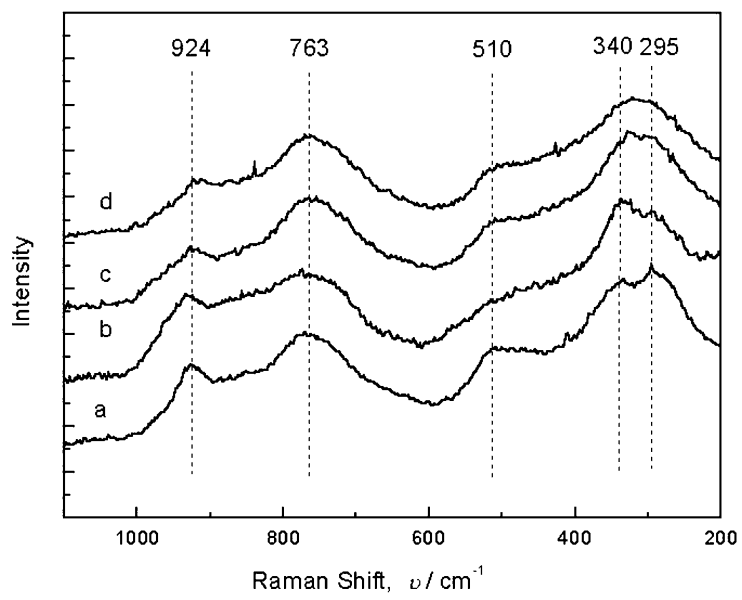

Fig. 2 Raman spectra of conversion coatings obtained from (a) MO1, (b) MA1, (c) MA2, (d) MA3 baths.

\section{Results and Discussion}

\subsection{Structure of conversion coatings}

The appearances of conversion coatings obtained with MO1 and MO2 baths showed colorful transparent films with the treatment time, ranging from a golden/blue to green film when the treatment time was less than $1 \mathrm{~min}$. But if the treatment time exceeds 1 min, dark-orange colored films were formed resulting in characteristic dried 'river-bed' cracked surface structure. But the appearances of conversion coatings obtained in the presence of $\mathrm{Al}$ showed metallic luster even after 5 min of immersion.

FE-SEM analysis showed that the thickness of conversion coatings obtained with MO1 bath for 5 min was approximately $1 \mu \mathrm{m}$. In Fig. 1, Mo content in conversion coatings

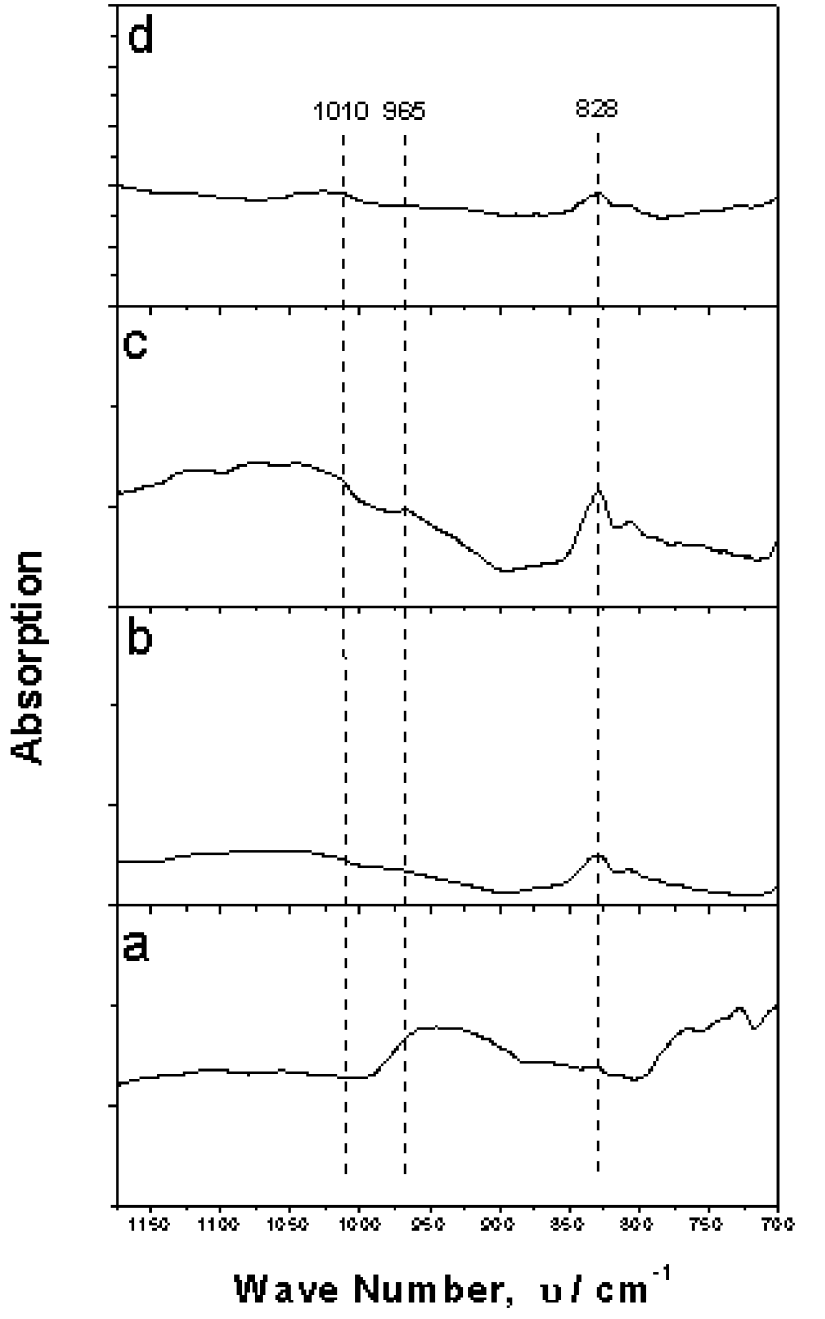

Fig. 3 Infrared reflectance spectra of conversion coatings obtained from (a) MO1, (b) MA2, (c) MA3 baths, and (d) electropolished aluminum electrode.

with a variation of dipping time in different baths are presented. Mo content in conversion coatings with MO1 bath exceeds 20 times than that in conversion coatings with MA2 and MA3 baths, which indicates that the rate of film formation reactions decreases with an increase of $\mathrm{Al}$ concentration. From the AES analyses, Al contents in the conversion coatings obtained with MA1, MA2, and MA3 baths for 5 min dipping are about $2-3$ at $\%$, and 6-8 at $\%$, and $11-12$ at $\%$, respectively. And zinc contents in the conversion coatings with MA1, MA2, and MA3 baths are about 1.5-3 at\% and 610 at $\%$, and 6-7 at $\%$, respectively. The $\mathrm{Al}$ content in the conversion coatings increases with the concentration of aluminum sulfate in bath. 

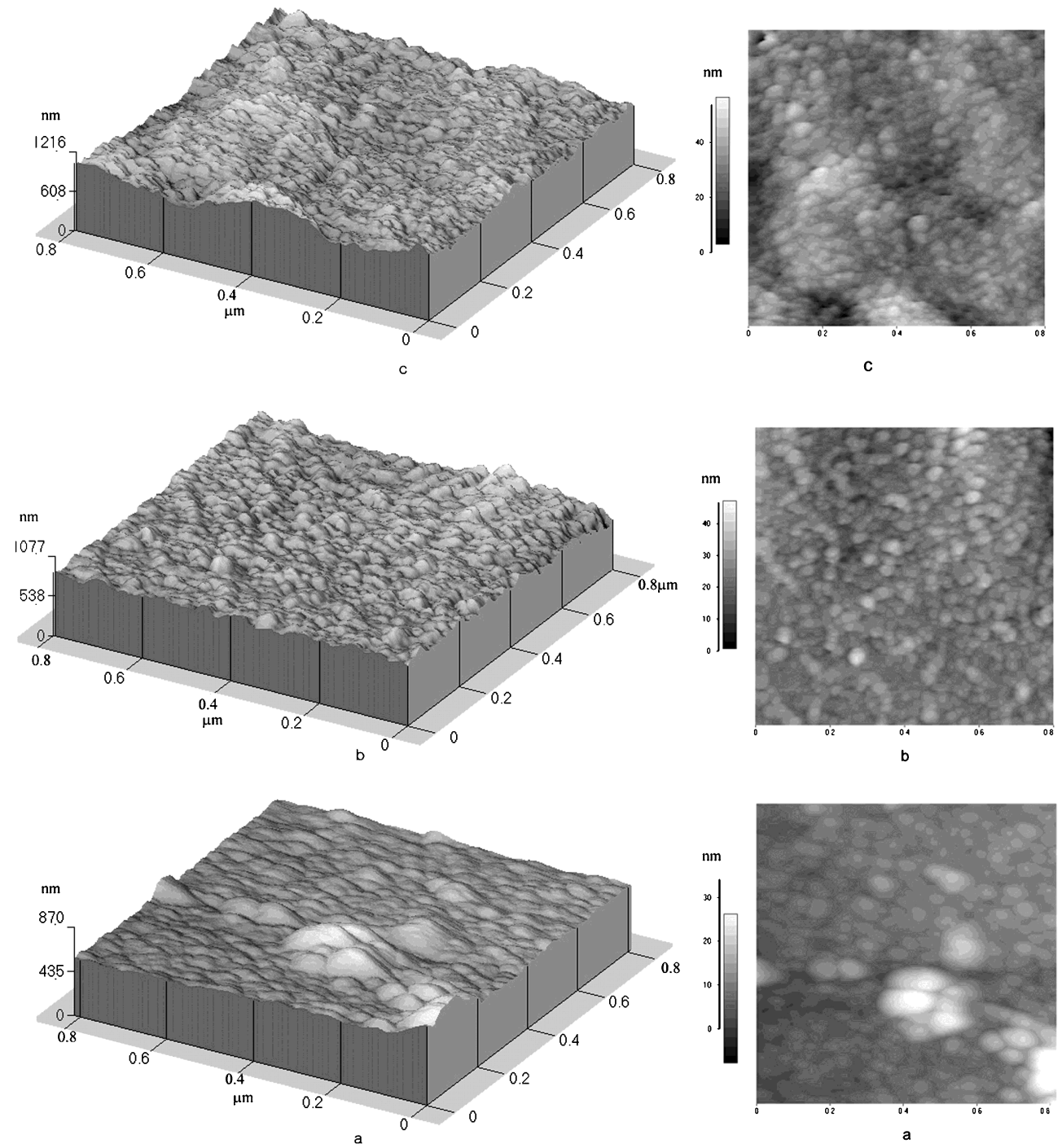

Fig. 4 AFM images of conversion coatings obtained from (a) MO1, (b) MA1, (c) MA2 baths.

Raman spectroscopy was employed to identify the species present in the coating and the results are shown in Fig. 2. The Raman shift at $924 \mathrm{~cm}^{-1}$ implies that the polymerized and octahedral cluster ions such as $\mathrm{Mo}_{7} \mathrm{O}_{24}^{6-}$ at $934 \mathrm{~cm}^{-111}$ ) or $\mathrm{Mo}_{8} \mathrm{O}_{26}^{4-}$ at $963 \mathrm{~cm}^{-111)}$ exists in the film. Considering that the major molybdate ion is $\mathrm{Mo}_{7} \mathrm{O}_{24}^{6-}$ at $\mathrm{pH}$ of 5.0 in the bath, ${ }^{11,12)}$ it is believed that $\mathrm{Mo}_{7} \mathrm{O}_{24}^{6-}$ is trapped during the formation of the film. The major Raman shifts of $\mathrm{MoO}_{2}$ were reported in the range from $740 \mathrm{~cm}^{-1}$ to $760 \mathrm{~cm}^{-113-15)}$ and no other molybdenum oxides have Raman shifts in this range, broad Raman shifts at $763 \mathrm{~cm}^{-1}, 512 \mathrm{~cm}^{-1}, 340 \mathrm{~cm}^{-1}$ can be assigned as $\mathrm{MoO}_{2}\left(760 \mathrm{~cm}^{-1}, 505 \mathrm{~cm}^{-1}, 365 \mathrm{~cm}^{-113}\right)$ and $748 \mathrm{~cm}^{-1}, 510 \mathrm{~cm}^{-1}, 360 \mathrm{~cm}^{-1}$. ${ }^{14)}$ So, the film may be composed of $\mathrm{MoO}_{2}$ and trapped $\mathrm{Mo}_{7} \mathrm{O}_{24}^{6-}$. Almeida et al. suggested that the film is composed of Mo(IV) compounds and $\mathrm{Mo}(\mathrm{VI})$ compounds from their XPS results, ${ }^{1)}$ and this is consistent with the above spectroscopic results. Figs. 2(b), (c), and (d) show that $\mathrm{Al}$ addition does not change Raman spectra of conversion coatings.

Figure 3 illustrates FT-IR data. A distinctive band appears at $828 \mathrm{~cm}^{-1}$ in the $\mathrm{Al}$-added molybdate conversion coatings and electropolished aluminum electrode. This band is obviously related to the Al species, most likely associated with an Al-OH vibration. ${ }^{16)}$ Also the bands at $965 \mathrm{~cm}^{-1}$ and $1010 \mathrm{~cm}^{-1}$ together with $828 \mathrm{~cm}^{-1}$ indicate that the Al hydroxide species is nordstrandite, ${ }^{17,18)}$ although the relative intensities of these bands are changed due to an amorphous nature of the conversion coatings ascertained by HR-TEM image. The relative intensity of these bands increases with the $\mathrm{Al}$ content in the conversion coating. In addition, the $\mathrm{AlO}-\mathrm{H}$ stretching bands in the range of $3000-3700 \mathrm{~cm}^{-1}$ cannot be distinguished from $\mathrm{MoO}-\mathrm{H}$ stretching bands.

Figure 4 shows the AFM images of conversion coatings. The images indicate that molybdate conversion coatings are composed of agglomerated particles of $10-50 \mathrm{~nm}$ size, irrespective of $\mathrm{Al}$ addition. In the case of conversion coatings obtained with MA2 which have enough Al addition, its roughness is slightly higher than the others, and the particle size of molybdate conversion coatings decreases with $\mathrm{Al}$ addition.

Based on the Raman, AES and IR spectra, Al added molybdate conversion coatings may be composed of nanosize $\mathrm{MoO}_{2}$, trapped $\mathrm{Mo}_{7} \mathrm{O}_{24}^{6-}$, aluminum hydroxides and zinc hydroxides. The deposition of $\mathrm{Al}$ and $\mathrm{Zn}$ species in the film is due to a local increase of $\mathrm{pH}$ caused by the cathodic reduction of molybdate near the surface of the substrate during the treatment. 


\subsection{Hydrogen evolution and oxygen reduction reactions}

It is well known that not only the anodic reaction but the cathodic reactions due to hydrogen evolution and/or oxygen reduction reactions are hindered on the chromated layer surface, compared with those of the other conversion coated surfaces, which gives the excellent corrosion resistance of chromate conversion coatings. ${ }^{19)}$ So the amount of reduction current on these coated surfaces can be one of the criterions of the corrosion resistance. Figure 5 shows cathodic polarization curves on molybdate conversion coatings with a scan rate of $2 \mathrm{mV} / \mathrm{s}$ in the $\mathrm{N}_{2}$ bubbled borate buffer solution. It shows a broad hump about $-1.0 \mathrm{~V}$, and the rest potential of molybdate conversion coatings increases with the Mo content of the film. The amount of cathodic current at the hump also increases with the Mo content. But the rest potential decreases and the hump is disappeared during the second scan, which indicate that the polymerized hexavalent molybdates in the film could also be reduced during the cathodic reduction process. Figure 6 presents the ex-situ Raman spectra obtained by controlling the potential of the electrode at $-1.2 \mathrm{~V}$ for $5 \mathrm{~min}$ in $\mathrm{N}_{2}$ bubbled borate buffer solution. The spectra show that the intensity of Raman shifts of polymerized molybdates is indeed weakened, irrespective of $\mathrm{Al}$ addition, which confirms that polymerized molybdates participate in cathodic reaction.

Since hexavalent molybdenum ions also can be reduced during the cathodic reaction as mentioned above, potentiostatic experiments at $-1.2 \mathrm{~V}$ were performed in advance to minimize the contribution from the reduction of molybdates in the film. Figure 7 shows potentiodynamic curves in borate buffer solution bubbled by $\mathrm{N}_{2}$ gas. As the content of $\mathrm{Al}$ in the coatings increases, the current density of hydrogen evolution reaction decreases, and as expected, the chromate conversion coatings effectively hinder the hydrogen evolution reactions.

Figure 8 illustrates the potentiodynamic cathodic polariza-

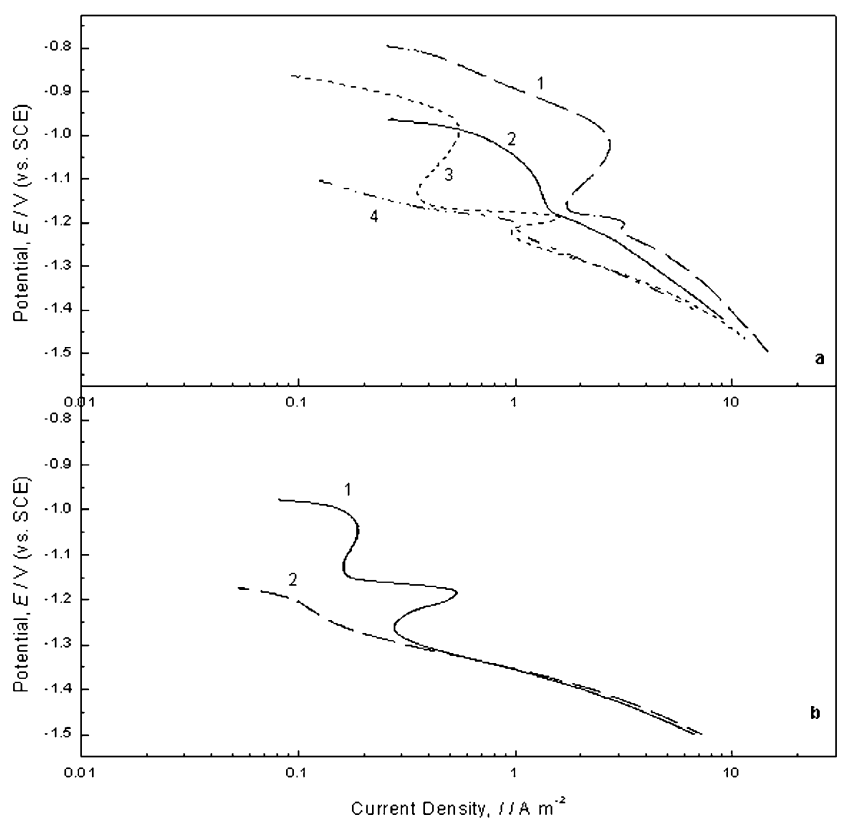

Fig. 5 Cathodic polarization curves on various conversion coatings obtained from (a-1) MO1 bath for $30 \mathrm{~s}$ at the first scan, and (a-2) at the second scan, (a-3) MO1 bath for 2 at first scan and (a-4) at second scan, (b-1) MA2 bath for $30 \mathrm{~s}$ at the first scan, and (b-2) at the second scan in $\mathrm{N}_{2}$ bubbled borate solution, respectively. Scan rate is $2 \mathrm{mV} \mathrm{s}^{-1}$. tion curves on different conversion coatings in $\mathrm{O}_{2}$ bubbled borate buffer solution. In $\mathrm{O}_{2}$ bubbled borate solution, the passive film of zinc oxides/hydroxides can be formed, ${ }^{20)}$ and it makes possible to maintain the rest potential of some conversion coatings at $-0.75 \mathrm{~V}$ without much dissolution of $\mathrm{Zn}$. In the potential range between $-1.1 \mathrm{~V}$ and $-1.15 \mathrm{~V}$, current density shown in Fig. 8 is very large in comparison with the current density shown in Fig. 7, which indicates that the major species participating in the cathodic reaction is dissolved oxygen. The electrochemical behaviors of various conversion coatings are similar with those obtained in $\mathrm{N}_{2}$ bubbled borate solutions. The reduction current of dissolved oxygen decreases with the increase of $\mathrm{Al}$ content in coatings, and it also decreases with the dipping time. And the oxygen reduction reaction on chromate coating is the most sluggish among the conversion coatings. These results indicate that the addition of $\mathrm{Al}$ in molybdenum conversion coating enhances the corrosion resistance compared with the case of simple molybdenum conversion coating.

\subsection{Anticorrosive property}

To test the anticorrosive property, the molybdate conversion coatings obtained with MO1, MA1, MA2, MA3 and $\mathrm{CH} 1$ bath for $30 \mathrm{~s}$, were immersed in 5 mass $\% \mathrm{NaCl}$ solution for $10 \mathrm{~h}$, and the amount of white rust produced was compared with each other. The amount of white rust produced on the molybdate conversion coatings with MO1 bath is as much as $40 \%$, and those of the conversion coatings with MA1 and MA2 are approximately $10 \%$, and that of the conversion coatings with MA3 is about 5\%, while no white rusts were observed on the chromate conversion coatings with $\mathrm{CH} 1$. These results agree well with the above electrochemical results which means that the addition of $\mathrm{Al}$ into molybdate conversion coatings enhances the anticorrosive properties significantly, considering that the Mo content in Al added molybdate

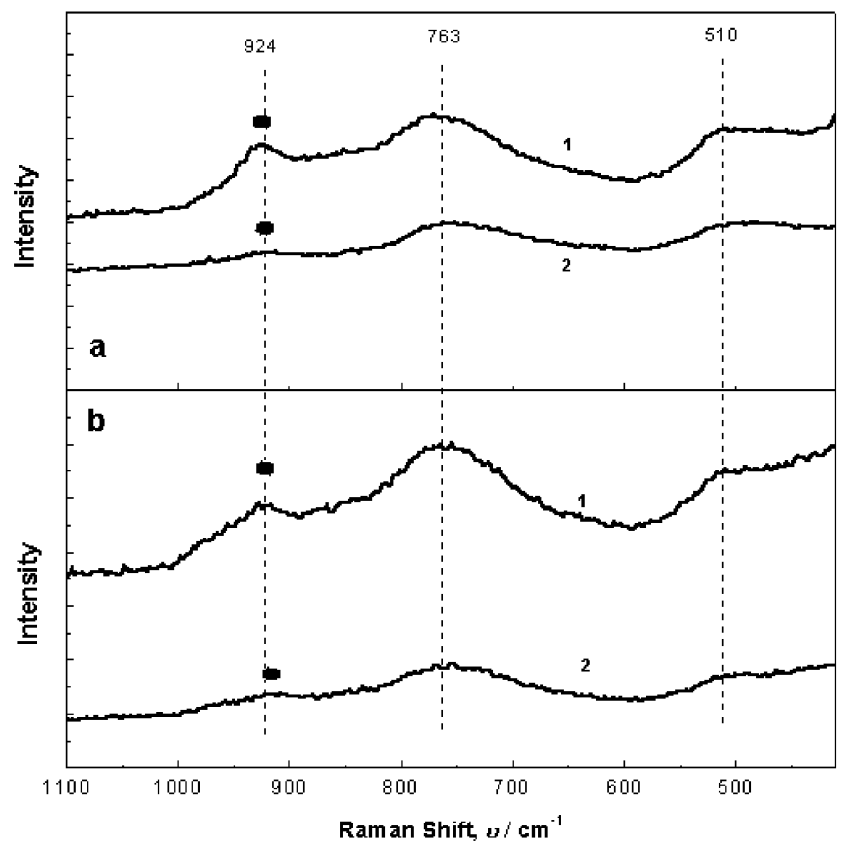

Fig. 6 Raman spectra of conversion coatings (a-1) as obtained from MO1 bath, (a-2) reduced at $-1.2 \mathrm{~V}$ (MO1 bath), (b-1) as obtained from MA2 bath, and (b-2) reduced at $-1.2 \mathrm{~V}$ (MA2 bath), respectively. 

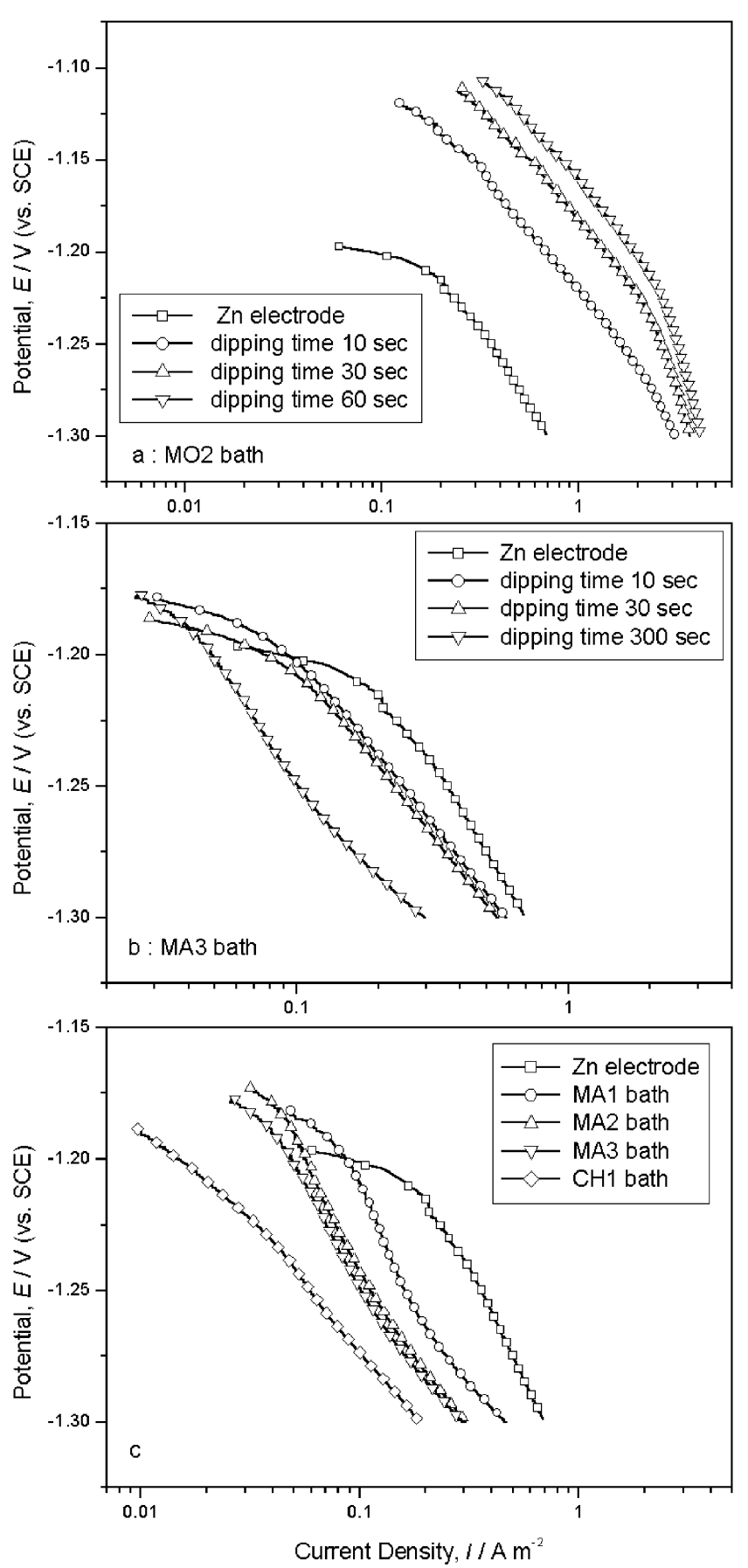

Fig. 7 Cathodic polarization curves of conversion coatings obtained from various treatment bath and dipping time in $\mathrm{N}_{2}$ bubbled borate solution with a scan rate of $0.17 \mathrm{mV} \mathrm{s}^{-1}$. (c: dipping time: $300 \mathrm{~s}$ ).

conversion coatings is approximately one twentieth of that in simple molybdate conversion coatings.

\section{Conclusions}

The structure and electrochemical properties of molybdate conversion coatings in the presence of aluminum sulfate were characterized with spectroscopic method and potentiodyndamic polarization techniques, respectively. The film formed on $\mathrm{Zn}$ substrate was mainly composed of nanosize $\mathrm{MoO}_{2}$ with polymerized molybdate ions. The addition of $\mathrm{Al}$ in molybdenum conversion coatings enhanced corrosion resis-
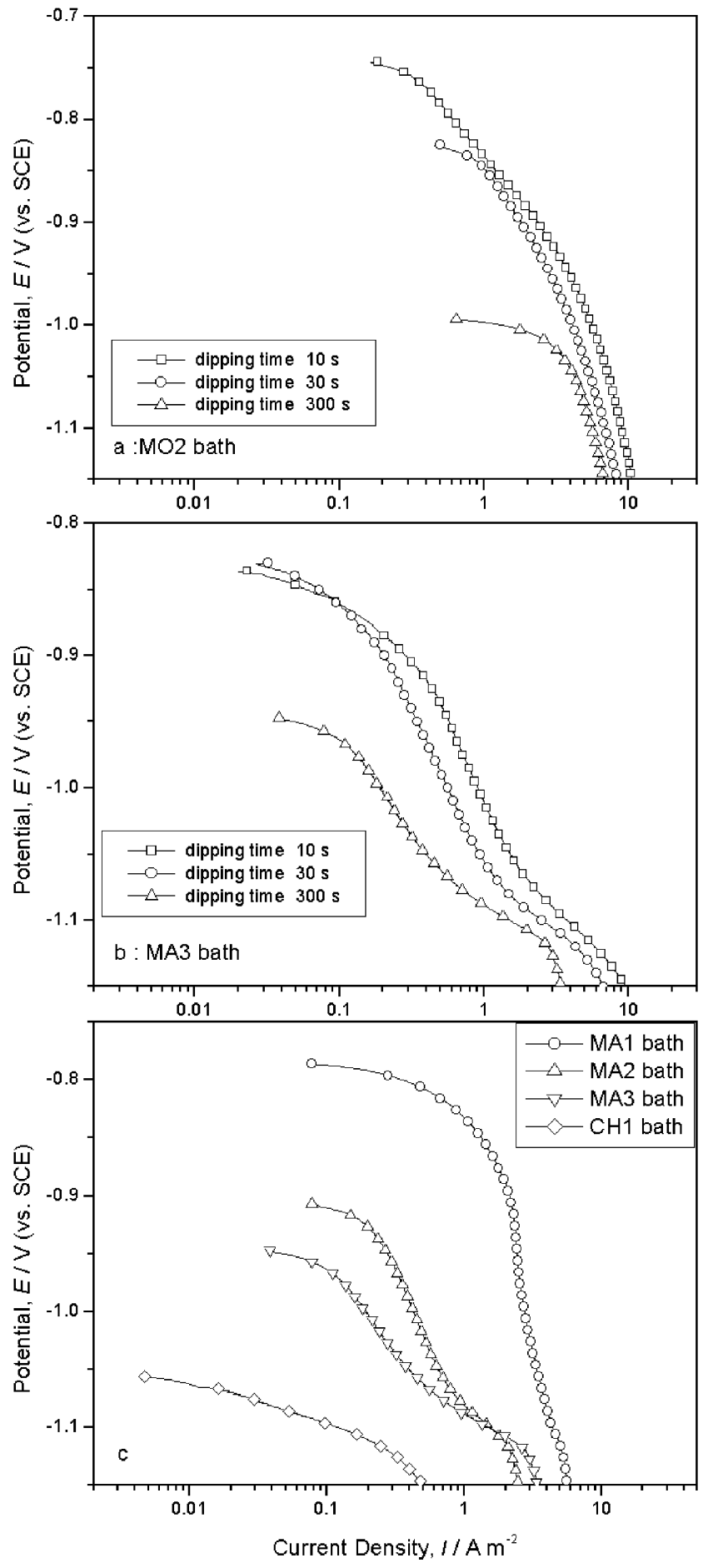

Fig. 8 Cathodic polarization curves of conversion coatings obtained from various treatment bath and dipping time in $\mathrm{O}_{2}$ bubbled borate solution with a scan rate of $0.5 \mathrm{mV} \mathrm{s}^{-1}$. (c: dipping time: $300 \mathrm{~s}$ ).

tance significantly which was confirmed by electrochemical techniques and direct corrosion tests.

\section{Acknowledgements}

This work was supported by the Pohang Iron and Steel Co., Ltd through BK 21 program of the Ministry of Education, Korea. 


\section{REFERENCES}

1) E. Almeida, T. C. Diamanino, M. O. Figueiredo and Carlos Sa: Surf. \& Coatings Technol. 106 (1998) 8-17.

2) J. A. Wharton, G. D. Wilcox and K. R. Baldwin: Trans. IMF 77 (1999) $152-158$.

3) G. D. Wilcox, D. R. Gabe and M. E. Warwick: Corros. Rev. 6 (4) (1986) 327-365.

4) E. Almeida, L. Fedrizzi and T. C. Diamantinio: Surf. \& Coatings Technol. 105 (1998) 97-101.

5) P. T. Tang, G. Bech-Nielsen and P. Møller: Plating \& Surf. Finish. 81 (11) (1994) 20-23.

6) G. M. Treacy, G. D. Wilcox and M. O. W. Richardson: J. Appl. Electrochem. 29 (1999) 647-654.

7) J. A. Wharton, G. D. Wilcox and K. R. Baldwin: Trans. IMF 74 (1996) 210-216.

8) F. Albert Cotton and Geoffrey Wilkinson: Advanced Inorganic Chemistry, 5th Edition (John Wiley \& Sons, 1988) pp. 808.

9) J. L. Fang, J. K. Wang, T. Q. Liu and Y. Wu: Plating \& Surf. Finish. 82 (6) (1995) 77-80.
10) K. Kurosawa and T. Fukushima; Corros. Sci. 29 (1989) 1103-1114.

11) J. Aveston, E. W. Anacker and James S. Johnson: Inorg. Chem. 3 (1964) 735-746.

12) Charles F. Baes and Jr. Robert E. Mesmer: Hydrolysis of Cations, (John Wiley \& Sons, 1976) pp. 256.

13) R. Srivastava and L. L. Chase: Solid State Commun. 11 (1972) 349353.

14) G. H. Smudde and P. C. Stair: Surf. Sci. 317 (1994) 65-72.

15) E. Payen, J. Grimblot and S. Kasztelan: J. Phys. Chem. 91 (1987) 66426648.

16) Ching-Feng Lin, Marc D. Porter and Kurt R. Hebert: J. Electrochem. Soc. 141 (1994) 96-103.

17) R. S. Alwitt: Oxides and Oxide Films, (Marcel Dekker Inc., 1976) pp. 183-184.

18) J. A. Gadsden: Infrared Spectra of Minerals and Related Inorganic Compounds, (Butterworths, 1975) pp. 54.

19) L. Fedrizzi, F. Deflorian, G. Boni, P. L. Bonora and E. Pasini: Progr. Org. Coat. 29 (1996) 89-96.

20) E. E. Abd El Aal: Corros. Sci. 42 (2000) 1-16. 